\title{
Perceived accessibility of childcare in Europe: a cross-country multilevel study
}

\author{
Özgün Ünver* ${ }^{*}$, Tuba Bircan and Ides Nicaise
}

\author{
*Correspondence: \\ Ozgun.Unver@KULeuven.be \\ Research Institute for Work \\ and Society (HIVA-KU \\ Leuven), University of Leuven, \\ Parkstraat 47, Box 5300, \\ 3000 Leuven, Belgium
}

\begin{abstract}
Perceptions of users regarding the accessibility of childcare services have been underresearched. The present study addresses this gap by looking into the effect of systemic level characteristics of the ECEC system on the perceived accessibility of childcare at the individual level. Perceived accessibility is composed of perceived affordability, availability, quality and physical accessibility of these services. The socio-ecological model at the micro-level and the model of institutional setting of ECEC (provision, regulation and financing) at the macro-level are combined in multilevel analyses. Our finding is that childcare is perceived to be more accessible in countries that (1) do not allow private commercial profit-making ECEC services for 3-6-year-old children, (2) adopt a unitary ECEC system where services for 0-3-year-olds and 3-6-year-olds are harmonised and (3) provide generous public support per 0-5-year-old child in the ECEC system. The latter has an even stronger effect on families with an income below average.
\end{abstract}

Keywords: ECEC, Childcare, Pre-school, Vulnerable groups, Disadvantaged groups

\section{Background}

Ensuring the access of every child to an inclusive and good-quality early childhood education and care (ECEC) is an important priority for governments as ECEC has a more profound and lasting effect on children's learning potential than any other intervention in their later lives at any other age, especially for disadvantaged children (Bowers et al. 2012; Cunha et al. 2006; Heckman 2006; Leseman 2009). An extensive body of literature recognises the social and economic benefits of ECEC for improved child well-being and learning outcomes, prevention of educational disadvantage, enhanced female employment, reduced (child) poverty, increased intergenerational social mobility and favourable outcomes later in life (Cunha et al. 2006; Leseman 2009; OECD 2012).

Although the initial focus on ECEC was to free up mothers' time so that they can take part in the labour market (Mahon 2002), in line with scientific evidence on the positive outcomes of ECEC for the children themselves, the European discourse started to focus more on high-quality, holistic, complex, integrated, inter-sectoral and inclusive provision (Herczog 2012). However, whether these services are effectively accessible is often overlooked by researchers and policy makers (Vandenbroeck and Lazzari 2014), even more so for disadvantaged children from low-income families (Fram and Kim 2008; Ghysels and Van Lancker 2011; OECD 2006, 2012; Sylva et al. 2007). The present study

(c) The Author(s) 2018. This article is distributed under the terms of the Creative Commons Attribution 4.0 International License (http://creativecommons.org/licenses/by/4.0/), which permits unrestricted use, distribution, and reproduction in any medium, provided you give appropriate credit to the original author(s) and the source, provide a link to the Creative Commons license, and indicate if changes were made. 
addresses this gap in the literature for it investigates whether the childcare services are perceived to be accessible in Europe, and how perceived accessibility is affected by the design of the ECEC system. It is important to study perceived accessibility of childcare, in order to see whether the investments done on the ECEC system translates into easier access perceived by parents who (would like to) use these services. Researching perceived accessibility provides both academics and policy makers with insight on whether various ECEC policies have a positive impact on people's lives.

\section{Perceptions of the accessibility of ECEC}

Before elucidating the theoretical understanding of policy effects on the accessibility of ECEC, it is crucial to appraise the wide array of research that has been investigating the perception of ECEC at the individual level. Although research on parental perception is essential, it is rarely investigated in both earlier and later stages of education (Anderson and Minke 2007; Cleveland et al. 2013). In particular, perceptions of disadvantaged families on early childhood education have not attracted much interest with the exception of a few studies (Fram and Kim 2008; Fuller et al. 1996; Henly and Lyons 2000; Vandenbroeck and Lazzari 2014), whose results are variant in terms of the dimensions of ECEC that they focus on such as preference motivations for home-based versus centre-based child care (Kim and Fram 2009; Li-Grining and Coley 2006), childcare arrangements (Henly and Lyons 2000), family processes (Fuller et al. 1996) and access to information about ECEC and enrolment procedures (Vandenbroeck and Lazzari 2014).

In the past two decades, research on parental preferences regarding the type and intensity of ECEC has gained interest (Gamble et al. 2009; Pungello and Kurtz-Costes 1999; Rose and Elicker 2010; Seo 2003; Vandenbroeck et al. 2008). Since then, parents' perception of ECEC quality is being studied in particular (Ceglowski and Bacigalupa 2002; Lehrer et al. 2015), also from the perspective of low-income families (Barbarin et al. 2006; Forry et al. 2013; Li-Grining and Coley 2006). Accessibility of the services also found its way in these studies.

Among these studies, Barbarin et al. (2006) identified the areas of interest for parents from different socio-economic and ethnocultural backgrounds in relation to public ECEC quality such as close home-school collaboration, dual language development and the emotional climate in the classroom. Accessibility-related traits such as flexible opening hours and convenient location were also listed as components of quality by the parents. The authors also noted that accessibility-related indicators were usually left out of scholarly conceptions of quality.

Li-Grining and Coley (2006), in their research regarding developmental quality and maternal views, studied whether childcare met children's needs for "healthy, engaging, and supportive environments" and mothers' preferences and needs for "affordable, accessible, and flexible care". In this context, accessibility refers to whether childcare meets the mother's standards, whether there are transportation problems and whether the mother feels that she has access to reliable childcare and a provider with similar values. Flexibility is related to whether the provider is flexible regarding hours of care and the mothers' work schedule. Accessibility-related traits such as flexible hours and convenient location were classified as "practical considerations" in relation to childcare quality by Lehrer et al. (2015). 
Regarding parental perceptions of quality, some authors listed accessibility as a feature of quality along with cost and convenience (Hofferth and Wissoker 1992). However, treating cost, convenience and accessibility as functions of quality in ECEC broadens the definition of quality immensely. From the perspective of childcare and education, quality is "an overarching multidimensional concept referring to the extent to which ECEC provides an environment that enhances child development and child wellbeing" (Leseman 2014). However, in order to start having an impact on child development and well-being, ECEC should be accessible in the first place. Hence, quality is more related to rather specific educational elements such as curriculum and pedagogy.

In 2001, the Organisation for Economic Co-operation and Development (OECD) defined accessibility as an umbrella term that encompasses geographical distribution (rural/urban) and proximity, affordability, flexibility and adequacy for different age groups as well as children with different needs (OECD 2001). The definition of the term remained unchanged ever since with small tweaks, and eventually, some scholars listed availability, physical access, cost and quality as key parental considerations in choosing the type and/or centre of child care (Davis and Connelly 2005; Peyton et al. 2001). The present study also adopts these four dimensions as the characteristics of accessibility for two reasons. Firstly, the definition with four dimensions covers all key aspects of the accessibility of the services. Note that flexibility and adequacy mentioned in the definition by OECD (2001) can be assessed as a part of availability and quality, respectively. Secondly, in this definition, quality is treated as a contributor to the general accessibility, not the other way around. In this manner, we can clearly distinguish between the quality of services children receive in childcare facilities from the affordability of cost, physical accessibility (geographic distribution, opening times, etc.) and the availability of services. Furthermore, in the context of this study, quality is treated as a dimension of accessibility only with regard to being an obstacle to childcare use or not. The quality of ECEC as regards child outcomes is not addressed.

Even though there has been research on the perceived accessibility in the past, none of the studies directly focused on the effect of policies on individuals' perception, certainly not in a comparative manner at the European level. By using multilevel modelling, the present study fills this gap by testing the effects of country- or system-level regulations on the level of accessibility perceived by the public across Europe. Such a methodology is beneficial in identifying the ECEC policy measures that have a stronger link with accessible ECEC services, as policy makers need to set priorities when putting new policies in place. Consequently, the countries that plan reforms in their ECEC systems can start from the most important elements that would bring higher returns on investment.

The three-pillared institutional setting of ECEC proposed by several authors to capture the complexity of the ECEC system at the institutions level is also adopted as the conceptual framework of this article. This model acknowledges the role of the government in the provision, regulation and financing of the ECEC system (McLean 2014; Meyers and Gornick 2003; White and Friendly 2012). Given the tradition of focusing on the public investment in any public service sector, including ECEC, it is important to widen the focus also to how and by whom the services are provided (White and Friendly 2012). In our previous research, we have adopted this model, established quantifiable determinants for each mode of intervention and measured the effects of these determinants on the take-up of ECEC services across Europe (Authors, unpublished article). We 
use the same framework in the present study to test the effects of the same indicators on the perceived accessibility of services.

\section{Institutional setting of ECEC: provision, regulation and financing}

Regarding provision, some countries with a more liberal welfare model opt for a predominantly market-driven approach to ECEC, while some others (e.g. Nordic countries) focus more on universal access. In general, public and publicly subsidised private ECEC provision for 3-6-year-olds is more widespread compared to 0-3-year-olds (Eurydice 2014). By encouraging private provision, the government limits public expenditure and relies on the basic market principle that entrepreneurship would balance the demand and supply. Accordingly, more competition is expected to result in cheaper, more efficient, responsive, innovative, flexible and high-quality services (Noailly and Visser 2009; OECD 2006; Penn 2009). Nonetheless, some studies argue that market-based provision leads to considerable heterogeneity in terms of availability, affordability and quality of ECEC, as profit-making providers reinforce inequalities for disadvantaged families (Bastos and Cristia 2012; Bennett 2004; Meyers and Gornick 2003; Noailly and Visser 2009; OECD 2006; Penn 2009; Sosinsky et al. 2007). In the light of these claims, our first hypothesis is that childcare services would be perceived to be less accessible if private profit-making provision is allowed in the country.

In order to make childcare services more accessible and equitable, governments introduce either a legal entitlement to ECEC (a guaranteed place for all children in a facility), free provision (ECEC is free even though there may not be guaranteed places) or some years of compulsory ECEC (Authors, unpublished article). Our hypothesis is that guaranteed places and/or free provision improve the perceived accessibility of services. Thus we test for these separately in our analyses. Furthermore, previous research prioritises availability over affordability. Accordingly, guaranteed availability of places is found to have a larger positive impact on maternal labour market participation and take-up of childcare than the affordability of services (Del Boca 2002; Farfan-Portet et al. 2011; Kreyenfeld and Hank 2000). Thus, the age from which entitlement is guaranteed may have a larger effect on perceived accessibility compared to the age when entitlement to free provision starts.

The pillar of regulation refers to the standards imposed by the government regarding the functioning of the ECEC services such as quality standards, fees, professional requirements and wages (White and Friendly 2012). Among these, the quality standards are of utmost importance. Three major types of quality (i.e. structural, process and outcome quality) in ECEC have been studied extensively over the years (Dumčius et al. 2014; NICHD 2002). Process and outcome quality depend more on the teacher-, family- and child-level determinants such as pedagogical practices, relationship quality and greater parental engagement (Dumčius et al. 2014). Hence, the state has more control over structural quality in terms of regulatory power as it refers to group size in ECEC facilities, minimum staff qualifications, child-to-carer ratio and staff wages (Burchinal et al. 2002; Dumčius et al. 2014; Phillips et al. 2000). The former three have been very popular among researchers and are referred to as the "iron triangle" in the literature (Phillipsen et al. 1997). Among these, minimum staff qualifications predict structural quality the best (Burchinal et al. 2002; Dumčius et al. 2014; Manning et al. 2017). Further, despite 
being left out of the iron triangle of structural quality measures, staff wages have also been shown to be a good predictor of structural quality (Phillips et al. 2000; Phillipsen et al. 1997). Even though the link between perceived accessibility of childcare and quality is less obvious, there may be an indirect link. For instance, one could expect higher quality to reduce accessibility, because it makes ECEC more expensive. Alternatively, more qualified staff are not just better, but also more socially sensitive educators-i.e., aware of the importance of ECEC in breaking cycles of disadvantage. Consequently, the two other hypotheses of this study are that both higher staff qualification requirements and higher staff salaries would lead to higher quality, which in turn, would contribute to higher perceived accessibility of ECEC services.

Note that there are other structural quality indicators that could have an effect on the accessibility of ECEC such as in-service training (continuous professional development) or the presence of a curriculum (Slot et al. 2015). When studying the effect of structural quality on process quality, Slot et al. (2015) found that none of these two variables had a significant effect on process quality-which refers to the child's day-to-day experiences in ECEC facilities (Leseman 2014). Considering the lack of evidence that ongoing professional training and curriculum have a positive impact on quality itself, we decided to focus on only two above-mentioned indicators of structural quality: teachers' qualification level, which has been one of the indicators in the 'iron triangle' of structural quality indicators, and teachers' salary level, which is proven to be a strong determinant of quality.

There are other regulation-related features of ECEC systems besides structural quality. One of them is the ECEC system being 'split' or 'integrated' (also referred to as 'unitary'). In split systems, the services for 0-3-year-old (day care) and 3-6-year-old (pre-school) children are delivered and managed in a different way, by different authorities. On the other hand, unitary systems harmonise the services and resources for both age groups and are managed by a single authority. The main advantage of unitary systems is their stronger focus on child development (rather than, for instance, child minding), which may also involve a stronger emphasis on equitable access and quality-especially for 0-3-year-olds (Eurydice 2014; Kaga et al. 2010; OECD 2012). On that account, we hypothesise that the perceived accessibility of services may be higher in countries where the ECEC system is unitary.

Another indicator of the way ECEC is regulated in European countries is the (de) centralisation of ECEC services across different levels of governance. Some governments opt for more decentralisation arguing that it promotes democracy and freedom of choice at the local level and that it reduces bureaucracy and overall cost (Neuman 2009). However, the effect of decentralisation on the accessibility of services is not certain yet. According to a research conducted in France and Sweden, access to ECEC decreased in the former for 0-2-year-olds (decentralised in the early 1980s), while it increased for 0-6-year-olds in the latter (decentralised in early 1990s) (Neuman 2009). Still, due to the decrease in quality, Sweden started to re-centralise the ECEC system in the 2000s by introducing curriculum and earmarked financing to pre-schools. Hence, (de)centralisation is certainly a key aspect of the ECEC system to be studied, especially with regard to its effect on access. The Eurydice report (2014) contains three indicators which could be used as proxies for (de)centralisation with regard to various aspects: (a) bodies 
responsible for the accreditation and evaluation of centre-based ECEC settings, (b) bodies responsible for capacity monitoring and forward planning of centre-based ECEC and (c) authorities responsible for funding centre-based ECEC. Looking closer at these data, we see that most European countries combine at least two of the three levels of authority: central, regional (if applicable) and local. Given the uncertainly behind the degree of (de)centralisation in each country, these indicators are not fit for use in statistical analyses at the moment.

Finally, the pillar of financing relates to the public and private investment in the ECEC system. The public-to-private spending ratio in the country varies, depending on the prevailing welfare regime, national wealth, whether the services are provided publicly or commercially, and whether the public services are universal or targeted at certain vulnerable groups (Bennett 2004; Myers 2000). In any case, sufficient public investment for the sector is essential for the services to be accessible because the higher the childcare cost, the lower is the probability of using childcare (Hofferth and Wissoker 1992). Moreover, public investment in ECEC also reflects the importance attached to ECEC by that country (Bennett 2004). One of our hypotheses regarding financing is that services are perceived as more accessible as the public spending per child in ECEC increases. The other hypothesis is, the lower the proportion of private funding (in particular from households), the higher the perceived accessibility will be.

As anticipated, the financing pillar contains other indicators as well, which would contribute to understanding whether there are equity measures in place. The Eurydice report (2014) lists three indicators with regard to the affordability of ECEC services: the average out-of-pocket childcare expense for parents, the type of financial support available to parents and the criteria to offer fee reductions. Yet, none of these indicators qualifies for usage in statistical analysis. The first indicator is not standardised across countries (some provide data as average and some provide the range of fees). The countries vary too much in the second one, where quite many of them do not provide data at all. Finally, the last one demonstrates that most countries take multiple measures in determining whether a fee reduction is needed-which becomes irrelevant if the country provides the services free of charge. Better indicators are needed to dive deeper into the effect of financing of ECEC on the perceived accessibility of these services.

\section{Data and methods}

In our empirical analysis of the relationship between the institutional setting of ECEC at the country level and perceived accessibility of ECEC at the individual level, we will test the following hypotheses.

Provision:

1. In countries that rely (partly) on private for-profit ECEC provision for older (3-6-year-old) children, perceived accessibility is lower.

2. The earlier the legal entitlement to ECEC starts, the higher the perceived accessibility.

3. The earlier the children are entitled to free provision, the higher the perceived accessibility. 
Regulation:

4. Perceived accessibility is higher in countries with unitary systems than in countries with split systems.

5. The higher the minimum qualification of ECEC staff is, the higher the perceived accessibility.

6. The higher the pre-school teacher wages are, the higher the perceived accessibility.

Financing:

7. The higher the public spending is per child, the higher the perceived accessibility.

8. The higher the proportion of funding from private sources, the lower the perceived accessibility.

9. The higher the proportion of daily fees (funding from households), the lower the perceived accessibility.

\section{Data}

Our dependent variable and micro-level control variables come from the third wave of the cross-sectional European Quality of Life Survey (EQLS 2012) conducted in 34 countries in 2011/12 (Molinuevo 2015), where one adult per household is interviewed. Note that in the multilevel analyses, the level-2 sample size is smaller due to the missing cases in country-level variables. Our units of analysis are adults responding on behalf of their households. Carried out every 4 years by Eurofound, EQLS includes questions regarding the accessibility of childcare in the four dimensions discussed above: availability, physical access, affordability and quality. To our knowledge, this is the only international survey that collects data regarding the accessibility of childcare.

\section{Method of analysis}

In the present study, we apply multilevel modelling because we look into the effect of higher-level (i.e. country- or system-level) variables on outcomes at the household level. Multilevel modelling has been used in perception-related studies in social sciences on a diverse set of topics including the relationship between welfare regimes and disability and self-perceived health (Foubert et al. 2014), the effect of immigrant integration policies on perceived group threat (Schlueter et al. 2013), ethnocentrism (Bircan 2012) and perceptions related to the economic, moral and social consequences of welfare state (van Oorschot et al. 2012). However, to our knowledge, there has been no study on the perceived accessibility of childcare services using this method. This makes our study a unique contribution to the field.

To assess the significance and goodness-of-fit of the models, we compare the deviances through a Chi-square test (also known as the 'likelihood ratio test') (Hayes 2006). We also calculate the intra-class correlation (ICC) for every model to check if the country-level independent variables introduced in the analyses help explain a previously unexplained portion of the variance in the data. ICC is calculated by dividing the level-2 variance by the sum of level-1 and level-2 variances and reflects the proportion of country-level variance that is explained by the model. The ICC of the null model is $10.40 \%$ 
which is sufficiently high to pursue a multilevel analysis. For the analyses, we use the linear mixed models function in IBM SPSS (IBM Corp. 2015). The models for all independent variables are reported in the tables. Notwithstanding, among the models with interaction terms with income, only the ones where both the interaction effect is significant and the overall model is better than the model without the interaction term are reported.

There is no clear consensus on the use of weights in multilevel analysis within the field of statistics (Cai 2013). Although some research suggests that multilevel modelling already assumes multi-stage sampling (Goldstein 2003; Hox and Kreft 1994; Kaplan and Elliott 1997; Muthén 1994), a solid body of literature argues the necessity of introducing sample weights to provide robustness against model misspecification (Asparouhov 2006; Carle 2009; Chantala et al. 2005; Pfeffermann et al. 1998; Pfeffermann 1993; Pfeffermann et al. 2006). In order to avoid biased estimates, we considered the sampling process in the model specification and applied sampling weights in our random intercept models. Moreover, the data were weighted also to acquire the descriptive statistics using the final national weights (Eurofound 2013a).

\section{Dependent variable}

The dependent variable of this study is the "perceived childcare accessibility index" (PCAI), which was obtained by combining four variables reflecting the four dimensions of accessibility. These four questions were asked only to the respondents who have previously stated that either 'they themselves or someone in their household' or 'someone close to them outside the household' have used childcare services in the past 12 months.

To what extent did each of the following factors make it difficult or not for you, or someone close to you, to use childcare services? $(1=$ very difficult, $2=$ a little difficult, $3=$ not difficult at all).

a. Q55a cost.

b. Q55b availability (e.g. waiting lists, lack of services).

c. Q55c access (e.g. because of distance or opening hours).

d. Q55d quality of care.

Before combining them, in order to ensure that all these four aspects can form a single latent construct, a categorical principal component analysis (CATPCA) was conducted. The findings indicate that all four variables load mainly onto one component both across the whole sample as well as in every country. This means that these four variables measure one latent concept. Hence, we are confident that our dependent variable measures perceived accessibility of childcare taking into account its four dimensions. However, for the multilevel analyses, we opted for a composite score assigning equal weights to all four dimensions in the latent construct in all countries.

The composite score was calculated in the same manner that Eurofound did for their analyses (Eurofound 2013b, p. 110). Accordingly, the values corresponding to the categories of responses for the variables q55a (cost), q55b (availability), q55c (physical access) and q55d (quality) are re-coded and thus, assigned equivalent weights. Variables were re-coded as follows: 


$$
\begin{aligned}
& \operatorname{Cost}\left(p_{i}\right): g_{1}\left(p_{i}\right)=\left\{\begin{array}{cc}
-1, & Q 55 a=1 \\
-0.5, & Q 55 a=2 \\
1, & Q 55 a=3 \\
0, & Q 55 a=98
\end{array}\right. \\
& \text { Availability }\left(p_{i}\right): g_{2}\left(p_{i}\right)=\left\{\begin{array}{cc}
-1, & Q 55 b=1 \\
-0.5, & Q 55 b=2 \\
1, & Q 55 b=3 \\
0, & Q 55 b=98
\end{array}\right. \\
& \text { Access }\left(p_{i}\right): g_{3}\left(p_{i}\right)=\left\{\begin{array}{cc}
-1, & Q 55 c=1 \\
-0.5, & Q 55 c=2 \\
1, & Q 55 c=3 \\
0, & Q 55 c=98
\end{array}\right. \\
& \text { Quality }\left(p_{i}\right): g_{4}\left(p_{i}\right)=\left\{\begin{array}{cc}
-1, & Q 55 d=1 \\
-0.5, & Q 55 d=2 \\
1, & Q 55 d=3 \\
0, & Q 55 d=98
\end{array}\right.
\end{aligned}
$$

As a result of summing up the response categories for each respondent with its allocated weight, the index is computed as follows:

$$
\text { Perceived childcare accessibility index }\left(p_{i}\right)=\sum_{j=1}^{4} g_{j}\left(p_{i}\right) \quad j=1, \ldots, 4
$$

To summarise, the category "very difficult" was assigned the value -1 , "a little difficult" the value -0.5 and "not difficult at all" the value 1 . This re-coding slightly corrects the non-normal distribution of responses. Given the wording of the response categories, it is possible that the three categories are not at an equal distance from each other. In the original coding, the presence of difficulties is measured with two categories, whereas the absence is measured with only one. Moreover, the majority of responses fall into the third category where the elements of cost, availability, physical access and quality of services 'do not make use difficult at all'. Since the questions are also negatively worded, the respondents are not given any option to rate accessibility in different levels of positivity.

When these values are added up, the perceived childcare accessibility index ranges between -4 and +4 and can be treated as a continuous variable. Since there are quite a number of people who responded "don't know" (DK) to either of these questions, in order not to lose information, the DK responses were re-coded as 0 . In this way, their responses to other variables are not lost and their DK reply corresponds to the middle choice. However, the respondents who responded DK to all four questions of accessibility were deleted from the analysis listwise, because they did not state any opinion. Respondents who "refused" to answer any one of the four questions were also excluded from the analyses because, unlike DK where the respondent is willing to respond but unable to do so, refusal means that the respondent is not willing to answer a question 
(Blohm and Koch 2009). Thus, the answers of a respondent who refrained from disclosing information on one or more aspects of the accessibility of childcare would not be reliable.

\section{Independent variables}

\section{Micro-level control variables}

The level-1 control variables were chosen based on the socio-ecological model proposed and developed by quite a number of scholars over the past two decades (Liu 2015; Pungello and Kurtz-Costes 1999; Rose and Elicker 2010; Seo 2003; Sibley et al. 2015; Tang et al. 2012; Vandenbroeck et al. 2008). This model suggests that we take into account various dimensions such as the child, the mother (and sometimes the father), the family and environmental characteristics, as well as maternal well-being and cultural beliefs and preferences with regard to childcare when identifying the determinants of the type and intensity of ECEC used. A similar list of variables is also used in a recent study on attitudes towards public childcare (Chung and Meuleman 2017). This framework also meets our needs in controlling for the individual-, household- or family-related factors that may affect the perception of childcare accessibility. Since EQLS does not contain data on all of these aspects, we included eight variables to control for the main determinants of ECEC use at the individual and/or household level. These are gender, age (continuous), employment status (at work or not at work), education level (below secondary vs. secondary or higher), partnership status (married or partnered vs. non-partnered) of the respondent, the degree of urbanisation (urban vs. rural) of the area where the respondent lives, whether childcare is used in the household and the self-assessed income level.

As a demographic variable, age is usually controlled for in perception studies (e.g. Bircan 2012). In the context of choice of childcare, maternal age is used as a more specific variable, although its effect is sometimes significant (Barnes et al. 2006), it mostly is not (Fram and Kim 2008; Sylva et al. 2007; Zachrisson et al. 2013). However, younger age at childbirth has been associated with less participation in formal childcare (Geoffroy et al. 2012). In this study, the age of respondent which was included as a control variable for generational differences may have an effect on how accessible services are perceived.

Likewise, gender is also controlled for as a demographic variable in this research. Note that in previous research employing the socio-ecological theory, gender is usually not controlled for, as the demographics in the model refer only to the mother (e.g. Geoffroy et al. 2012; Sylva et al. 2007; Tang et al. 2012; Zachrisson et al. 2013). Nevertheless, there is proof that women and men may differ in their needs of social support (Rosenthal et al. 1986), which may, in turn, cause them to have differing standards when it comes to the accessibility of childcare.

Level of (parental) education attained is another control variable taken into account in this study, because education level is significantly associated with the choice of ECEC use (Sibley et al. 2015) and the use of formal or parental care (Geoffroy et al. 2012; Tang et al. 2012).

Similarly, employment status (being at work or not at work) is also significant in determining the childcare preference of mothers (Geoffroy et al. 2012; Tang et al. 2012); hence, it is included as a control variable. 
The partnership status of the respondent (married or partnered vs. non-partnered) is also included as a control variable for it reflects the presence of alternate caregivers in the household. Nonetheless, except for the decision to use childcare before the child reaches 18 months of age (Zachrisson et al. 2013), this variable is found to have a significant effect on neither the type or intensity of childcare use (Geoffroy et al. 2012; Sylva et al. 2007; Tang et al. 2012), nor the attitudes towards public childcare provision (Chung and Meuleman 2017).

Literature suggests that residents of rural areas have a lower chance to access childcare services compared to the ones who live in urban areas (Habibov 2012; Liu 2015). Accordingly, the degree of urbanisation is also controlled for in the analysis.

Another key control variable was whether a child from the household receives childcare services or not, as individuals who use the services personally may assess the accessibility differently.

Finally, we also control for the self-assessed income level of respondents as a proxy for their socio-economic status (Chung and Meuleman 2017) using the following variable:

Q57. Could you please evaluate the financial situation of your household? In comparison to most people in [COUNTRY], would you say it is: Much worse, somewhat worse, neither worse nor better, somewhat better, much better

We combined the first two and last two responses and created a three-category variable of the worse, average and better income. Besides testing our hypotheses regarding the institutional setting of ECEC for the whole sample, we also check whether the effects are stronger or weaker depending on the childcare use status and self-proclaimed income level of the respondents.

There are no missing data for age, gender, childcare self-use and employment status. However, there are some missing values in the form of refusals or "don't know" in relation to education level, the degree of urbanisation, partnership status and income self-assessment. None of the missing data follows a particular pattern when we crosstabulate them by country, gender, childcare use or employment status. Assuming that these variables were missing at random, we exclude the cases with missing variables from the analyses. For the descriptive statistics of micro-level control variables, see Table 1.

\section{Macro-level independent variables}

In a previous study, we researched the effect of the institutional setting on the take-up of ECEC services (Authors, unpublished article). In the present study, we use the same macro-level variables to be able to compare and contrast the effect of the institutional setting on the take-up of the services with their perceived accessibility. For the descriptive statistics of the independent variables, see Table 2.

We use three variables for provision: The first one is a binary variable reflecting whether or not the country allows for self-financing private provision at all for children aged 3-6 (data for the school year 2012-2013) (Eurydice 2014). Since it is more common to have commercial provision for younger children in Europe, private provision for 3-6-year-old children may be an indication of that country excluding pre-school from its mainstream education system. The other two variables for the provision segment are 
Table 1 Descriptive statistics of micro-level variables (EQLS 2012 weighted, $n=7213$ )

\begin{tabular}{|c|c|c|c|c|}
\hline & Mean or \% & St. Dev. & Min & Max \\
\hline \multicolumn{5}{|l|}{ Dependent variable } \\
\hline Perceived accessibility index & 0.94 & 2.37 & -4 & 4 \\
\hline \multicolumn{5}{|l|}{ Level-1 control variables } \\
\hline \multicolumn{5}{|l|}{ Continuous variables } \\
\hline Age of the respondent & 43.09 & 15.51 & 18 & 95 \\
\hline \multicolumn{5}{|l|}{ Categorical variables } \\
\hline \multicolumn{5}{|l|}{ Gender } \\
\hline Male & 43.7 & & & \\
\hline Female & 56.3 & & & \\
\hline \multicolumn{5}{|l|}{ Employment status } \\
\hline Not at work & 40.2 & & & \\
\hline At work & 59.8 & & & \\
\hline \multicolumn{5}{|l|}{ Education level } \\
\hline Secondary or lower & 66.4 & & & \\
\hline Post-secondary & 33.6 & & & \\
\hline \multicolumn{5}{|l|}{ Income self-assessment } \\
\hline Worse than average & 18.6 & & & \\
\hline Average & 50.6 & & & \\
\hline Better than average & 30.9 & & & \\
\hline \multicolumn{5}{|l|}{ Urbanisation } \\
\hline Countryside or village & 42.8 & & & \\
\hline Town or city & 57.2 & & & \\
\hline \multicolumn{5}{|l|}{ Marital/partnership status } \\
\hline Non-partnered & 32.0 & & & \\
\hline Married or partnered & 68.0 & & & \\
\hline \multicolumn{5}{|l|}{ Childcare use } \\
\hline Only outside the household & 52.7 & & & \\
\hline In the household & 47.3 & & & \\
\hline
\end{tabular}

the starting age of legal entitlement and starting age of free provision (Eurydice 2014). Both legal entitlement and free provision variables refer to the earliest age (in months) where children can receive these services in the school year 2012-2013. For countries that do not provide either of these services, we assigned the start of compulsory education (pre-primary or primary) as the corresponding value in both variables, because compulsory education means both legal entitlement and free access to school. For federal countries (e.g. Belgium, Germany, UK), the values for the great majority of the country are adopted.

As for regulation, we check whether the ECEC system being split or unitary has an effect on the perceived accessibility of services (Eurydice 2014). The nominal variable has three categories-split, mixed and unitary-where 'mixed' refers to some measures having been taken towards unification while the childcare and pre-school systems are not completely integrated yet. The second and third variables in the regulation segment refer to the structural quality of ECEC services, measured via the minimum qualification of professionals in 2012-2013 (Eurydice 2014) and the salary of staff working in pre-schools in 2013 (Education at a Glance 2015). The former is measured in years of post-secondary education received, and the latter in thousand Dollars converted to PPPs. 
Table 2 Descriptive statistics of independent variables

\begin{tabular}{|c|c|c|c|c|c|}
\hline & Mean or \% & St. Dev. & Min & Max & Sample size $(n)$ \\
\hline \multicolumn{6}{|l|}{ Continuous variables } \\
\hline Start of legal entitlement (age in months) & 44.30 & 22.36 & 6 & 84 & 30 \\
\hline Start of free provision (age in months) & 47.33 & 21.60 & 0 & 84 & 30 \\
\hline $\begin{array}{l}\text { Staff qualification level for 3-6 year-olds (years after } \\
\text { secondary education) }\end{array}$ & 3.07 & 1.25 & 0 & 5 & 30 \\
\hline $\begin{array}{l}\text { Teachers' salary after } 10 \text { years of service (PPP in thou- } \\
\text { sands) }\end{array}$ & 34.30 & 17.19 & 10.94 & 91.20 & 20 \\
\hline $\begin{array}{l}\text { Spending per child in care or education ( } 0-5 \text { year-olds) } \\
\text { (PPP in thousands) }\end{array}$ & 24.74 & 16.48 & 5.39 & 73.57 & 24 \\
\hline $\begin{array}{l}\text { Percentage of total education expenditure in ISCED } 0 \\
\text { from private sources }\end{array}$ & 11.57 & 9.14 & 0 & 27.8 & 27 \\
\hline $\begin{array}{l}\text { Percentage of total education expenditure in ISCED } 0 \\
\text { from households }\end{array}$ & 10.89 & 8.10 & 0 & 26.8 & 17 \\
\hline \multicolumn{6}{|l|}{ Categorical variables } \\
\hline Existence of private centre-based ECEC (3-6 year-olds) & & & & & 30 \\
\hline Non-existent & 50.0 & & & & \\
\hline Existent & 50.0 & & & & \\
\hline ECEC system being split or integrated & & & & & 31 \\
\hline Split & 51.6 & & & & \\
\hline Mixed & 19.4 & & & & \\
\hline Integrated & 29.0 & & & & \\
\hline
\end{tabular}

The effect of financing on perceived accessibility is also measured with three variables. Public expenditure per child in ECEC settings measures the public spending for care and education of 0-5-year-olds in the year 2011 in thousand Dollars converted to PPPs (OECD Family Database 2011) as the generosity of support from the government. Two variables are used to account for private sources of funding: the proportion of funding for ISCED 0 from private sources and the proportion of funding for ISCED 0 from households (Education at a Glance 2013). These two variables measure only the expenditure for 3-6-year-olds, the less privatised segment of ECEC. While the former takes into account all types of private funding, the latter measures only the funding that comes from households that use the system.

\section{Results}

The average perceived childcare accessibility index (PCAI) results across countries is shown in Fig. 1. Respondents in the Nordic countries (Sweden, Finland, Iceland and Denmark) find childcare much more accessible compared to the European average. They are followed by Cyprus, Netherlands, Austria, Belgium, Lithuania, Luxembourg, Bulgaria, Croatia and Germany, while the rest falls below the European average. Figure 2 shows how accessible childcare services are perceived by the respondents with below- versus above-average income (subjectively compared to their country average). In this figure, the countries are ranked according to their average scores for perceived accessibility by lowincome families. Note that the PCAI ranges between -4 and +4 . Overall, the ranking of countries differs slightly from the ranking shown in Fig. 1. With the exception of Lithuania and Spain, lower-income people find childcare less accessible compared to higherincome people. Even for people with a below-average income, the Nordic countries 

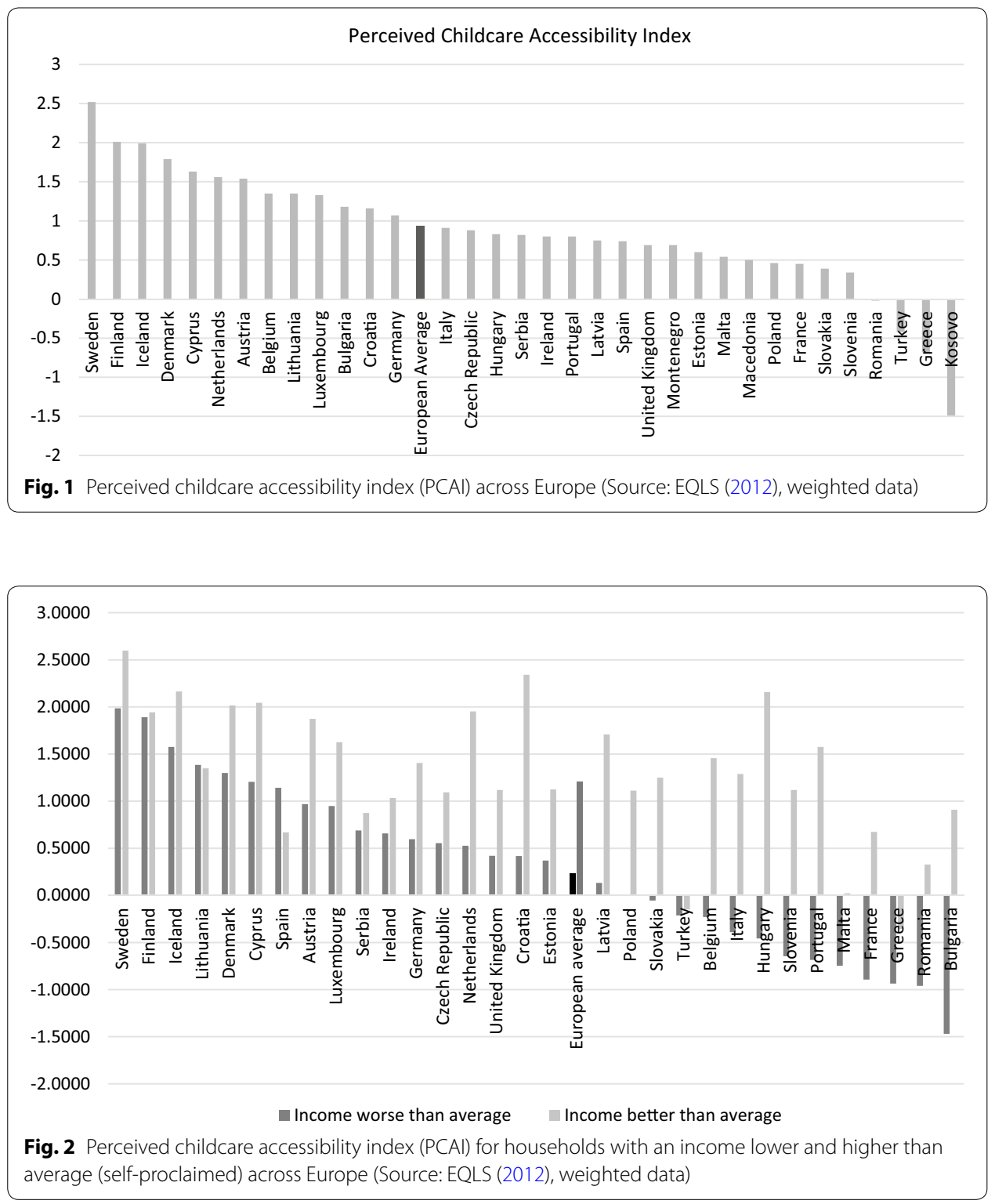

lead the way in accessibility, while some Southern and Eastern European countries tend to score poorly. The gap between the average PCAI for lower- and higher-income people at the country level is usually smaller in Northern and Western European countries, whereas it gets extremely large for Southern and Eastern European countries such as Croatia, Hungary, Portugal and Bulgaria. Only in Finland, Lithuania and Serbia; the scores are very equal. Moreover, there are striking outliers in terms of inequality: the scores of the low-income group drop far below the European average for countries such as Belgium and Bulgaria, where the average PCAI is relatively high (Fig. 3).

The null model with the PCAI as the dependent variable exhibits an intra-class correlation (ICC) of $10.40 \%$, which is the proportion of the variance to be explained at the country level. When Model 1 is fitted with only the eight level- 1 control variables, the ICC increases to $10.70 \%$ even though all parameters except for the partnership status 


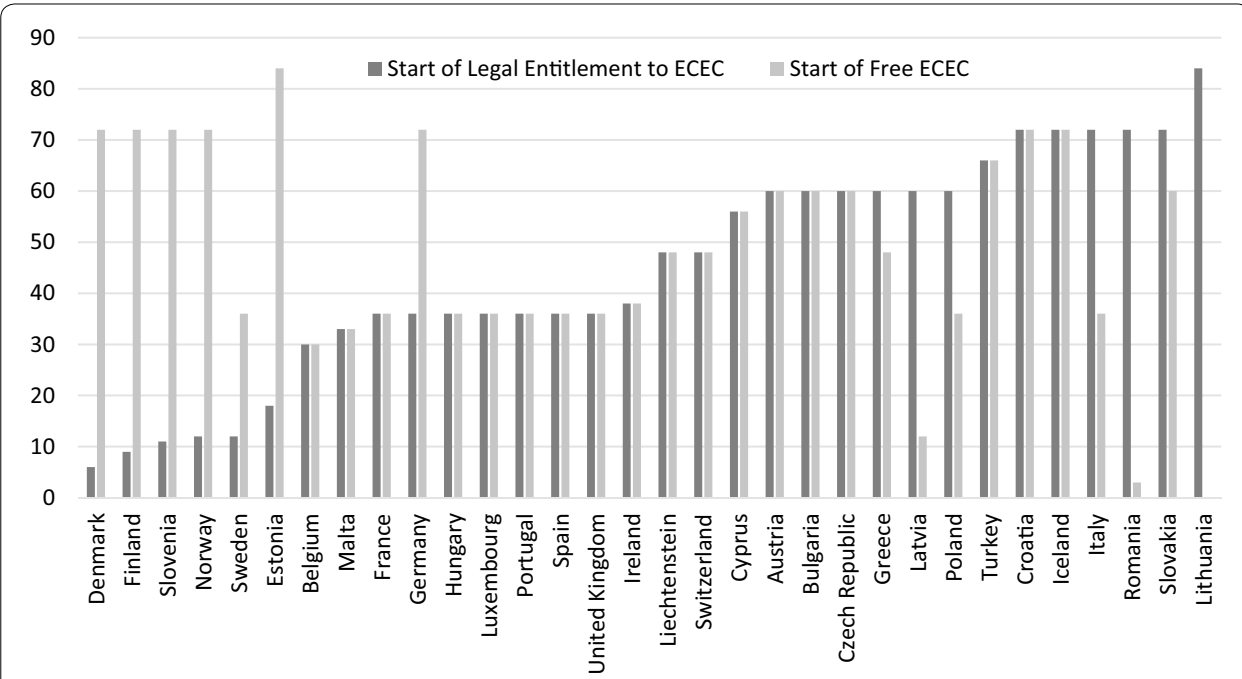

Fig. 3 Starting month of legal entitlement to ECEC and free ECEC (any number of hours in education or childcare) (Source: Eurydice (2014))

are significant (Table 3). To shortly summarise, the effects of the control variables, male respondents and respondents who are older, non-employed, living in rural areas and with above-average income reported higher perceived accessibility. Furthermore, as expected, respondents who use childcare services themselves report higher perceived accessibility. Education at secondary or higher level is only marginally significant in the baseline model, with differing significance levels in the presence of the different level-2 variables. Marital or partnership status is not significant in the baseline model, and does not stay significant in all other analyses in the presence of level-2 independent variables. The effect sizes of most individual-level variables remain similar throughout the multilevel analyses, and their significance levels remain mostly unchanged. This means that regardless the demographics of the respondents, the extent to which they find childcare services accessible depends on the country they live in, and thus, the childcare policies in place in the country.

As discussed earlier, the reason for higher perceived accessibility reported by males could be due to men and women having different needs and criteria to assess accessibility. Similarly, older age is already associated with more participation in childcare (Geoffroy et al. 2012), which could be the reason why older people reported higher accessibility. Not being at work would decrease the acute need for childcare, which may be the reason why non-employed respondents reported higher accessibility compared to employed respondents. Although previous research revealed that access to childcare is more difficult in rural areas (Habibov 2012; Liu 2015), however, this argument is not supported by our results. In some countries, it is easier to access childcare in rural areas due to lower demand, while in others, provision is limited in rural areas which leads to difficulty in access (Eurydice 2014). In this research, the respondents from urban areas reported lower accessibility probably due to the high demand in cities. Respondents with higher education reported higher accessibility only marginally, which is not completely in line with previous research that revealed higher use of formal childcare by higher 
educated people (Geoffroy et al. 2012; Tang et al. 2012). Not surprisingly, respondents who reported higher income than average, also found childcare to be more accessible compared to people with average or low-income levels. Finally, users of services reported higher accessibility compared to respondents who do not use childcare, as nonuser respondents may be unable to access the services in the first place.

As per our first hypothesis, we checked whether the presence of private (unsubsidised) provision for 3-6-year-olds makes a difference in perceived accessibility (Model 2). Our analysis confirms that in countries where no private provision is available, perceived accessibility of childcare services is higher. Thus, the first hypothesis is confirmed. However, no significant interaction of this variable with the perceived income level of the respondents is found. In other words, the existence of private for-profit provision tends to make ECEC less accessible for everyone living in the country, regardless of income level.

Our second hypothesis is that an earlier age of the legal entitlement enhances the accessibility of childcare (Model 3). The effect size is marginally significant. When controlling for the interaction effect of legal entitlement age and self-proclaimed income, the model does not improve. Hence, our hypothesis is rejected and we cannot confirm that earlier legal entitlement leads to a higher perceived accessibility of childcare services.

The final hypothesis for the provision pillar is that free ECEC hours at a younger age have a favourable effect on the perceived accessibility of childcare (Model 4). Neither this variable nor its interaction with self-proclaimed income level has a significant effect on the PCAI. Accordingly, we cannot confirm that earlier free entitlement to ECEC services contributes to the perceived accessibility of childcare.

In the pillar of regulation, our first hypothesis that unitary ECEC systems would lead to a higher perceived accessibility of childcare is confirmed (Model 5). Nonetheless, the PCAI was only marginally affected in countries with mixed systems, but significantly in those that have fully achieved unification. These countries are Iceland, Norway, Sweden, Finland, Latvia, Lithuania, Estonia, Croatia and Slovenia. Apart from the positive effect of integrated ECEC systems, none of the structural quality variables yielded positive results. Whether teachers working with 3-6-year-olds receive longer post-secondary education and whether these teachers earn higher salaries do not affect the public perception regarding childcare accessibility (Models 6 and 7 in Tables 3 and 4).

The effect of public spending per 0-5-year-old child in ECEC was the first to be tested when it comes to financing (Model 8). As expected, the perceived accessibility of childcare increases with the spending per child. Moreover, the interaction term of this variable with self-proclaimed income level reveals that this positive effect of higher spending per child is most appreciated by low-income families (Model 9). Contrary to our expectations, however, the proportion of funding for ISCED 0 (pre-school) coming from private sources in general (Model 10), and from households in particular (Model 11) does not have significant effects on PCAI. Thus, although the generosity of public spending is crucial for perceived accessibility, we cannot confirm that lower contributions from households as a whole lead to lower perceived accessibility.

Throughout the analyses, we controlled for the interaction terms of the countrylevel independent variables with both self-assessed income level of the respondent and whether the respondent lives in a household that uses childcare services. None of the 
interaction terms with childcare use were significant. Thus, the perceptions of the users and the ones who do not (directly) use the services are not affected differently by the system-level variables. With regard to the income level, except for the variable public spending on ECEC per child, none of the independent variables have significant interaction terms leading to better models either. In the cases of unitary systems and the earlier start of legal entitlement, we found marginally significant interaction terms with average income, suggesting that these two system features benefit families with average income most. However, these models were not significantly better than the models without interaction terms. Since we cannot derive clear conclusions with regard to these effects, these models are not reported in the tables.

All of these models with level-2 variables were also controlled for GDP per capita to check for robustness (Table 5). We used the 2011 GDP per capita information already provided in the EQLS dataset in PPS. GDP per capita has also a significant link with the accessibility of childcare: as expected, the wealthier the country, the more accessible is childcare. When models were augmented with GDP per capita, the results for most variables of the institutional setting of ECEC were found not to change. However, there are two exceptions. Foremost, teachers' salary variable becomes marginally significant when controlled for GDP per capita, although it does not seem to have a significant link when modelled on its own. Moreover, the interaction term of teachers' salary and GDP per capita yields a negative effect, which reflects that teachers' salary is significantly related to the accessibility of childcare in countries with a lower GDP per capita. Assuming that pre-school teachers' salary level to some extent demonstrates the importance given to ECEC in a country; having a higher pre-school teacher salary rate despite a not so high GDP per capita can be interpreted as there is an overall inclination to make childcare perceived as more accessible for all children in that country.

The second exception is related to the spending per child in ECEC. When modelled in combination with GDP per capita, the effect of this variable keeps its significance, but the main effect of GDP per capita becomes not significant. When we checked the interaction term to understand better what this result meant, we found that the interaction of spending per child and GDP per capita has also a negative effect. This implies that in countries with a higher spending per child in ECEC, childcare becomes even more accessible if the GDP per capita in that country is on the lower side. Similar to the explanation for teachers' salaries, we argue that if a country invests more on ECEC despite financial hardships, perceived accessibility of childcare increases significantly. These results are very encouraging to argue that ECEC should be prioritised even in times of austerity. From the accessibility point of view, these results demonstrate that investment pays off. 


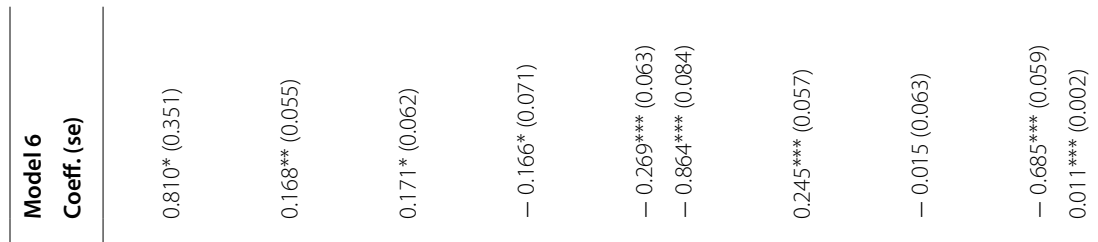

i1) $11 \| 1 \mid$

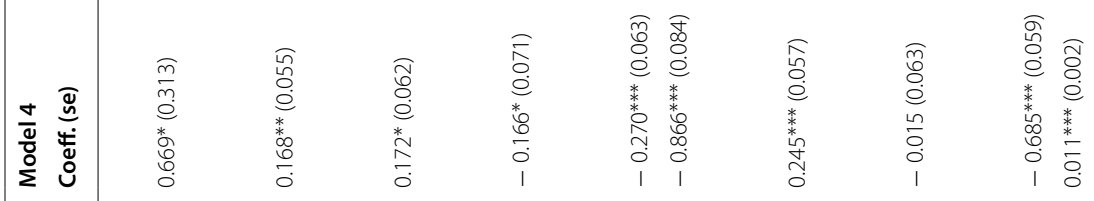

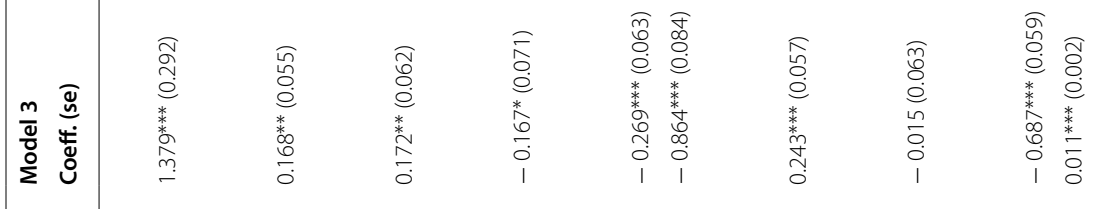

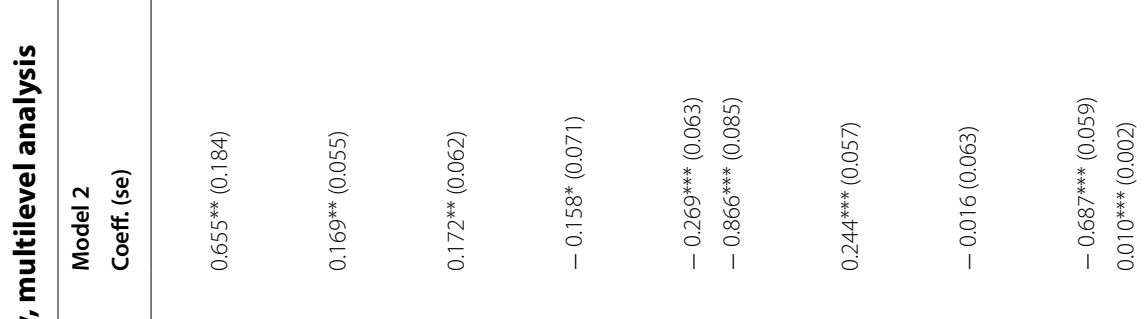

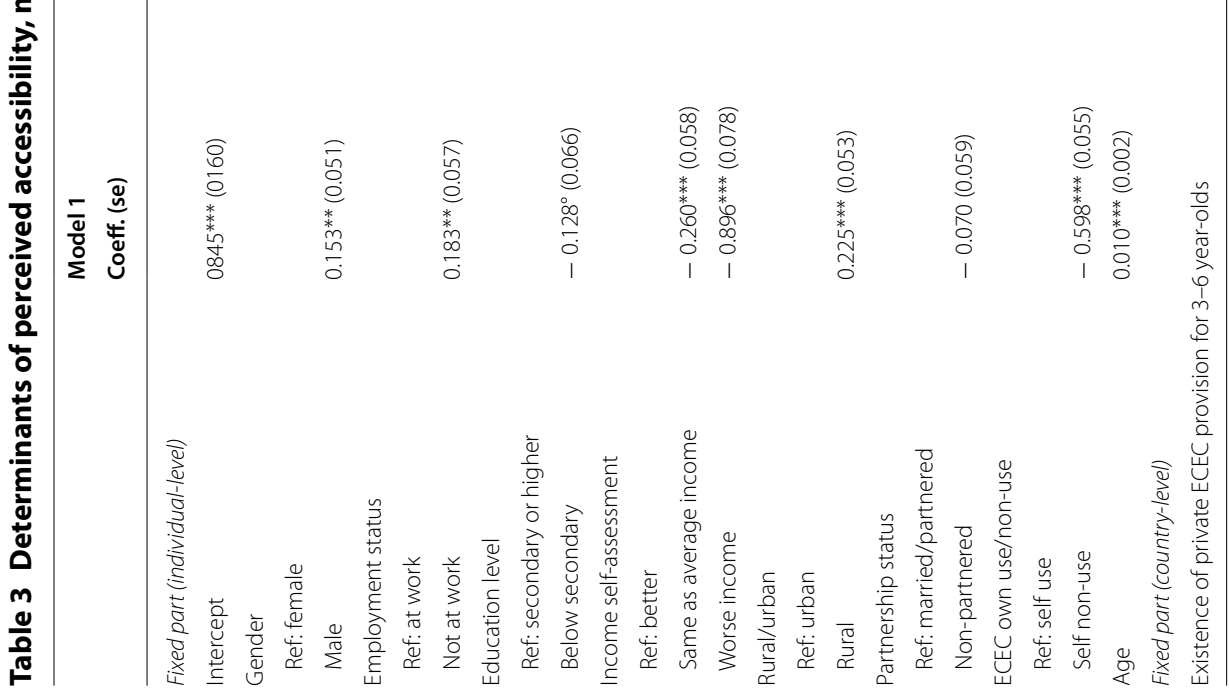




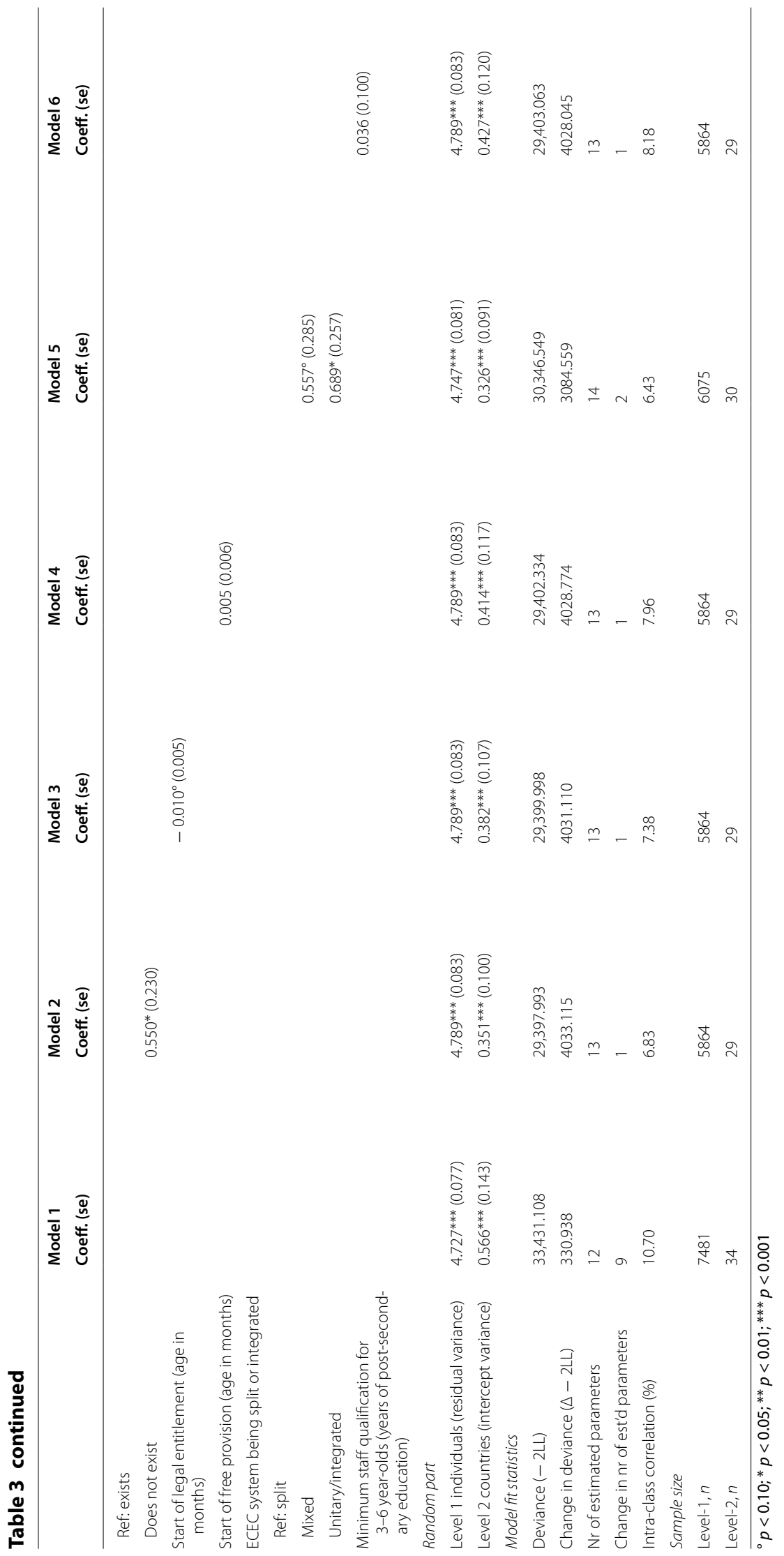




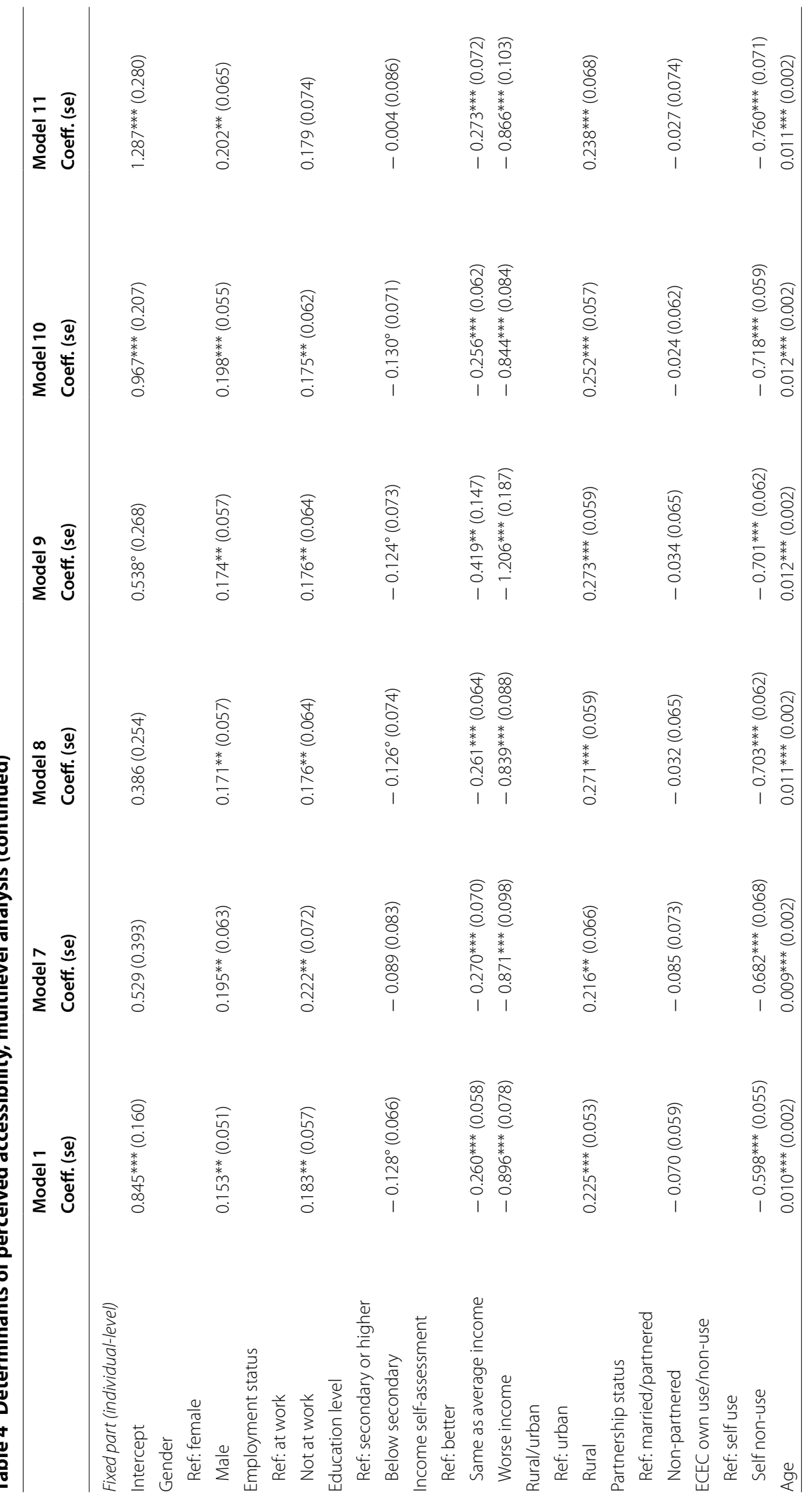




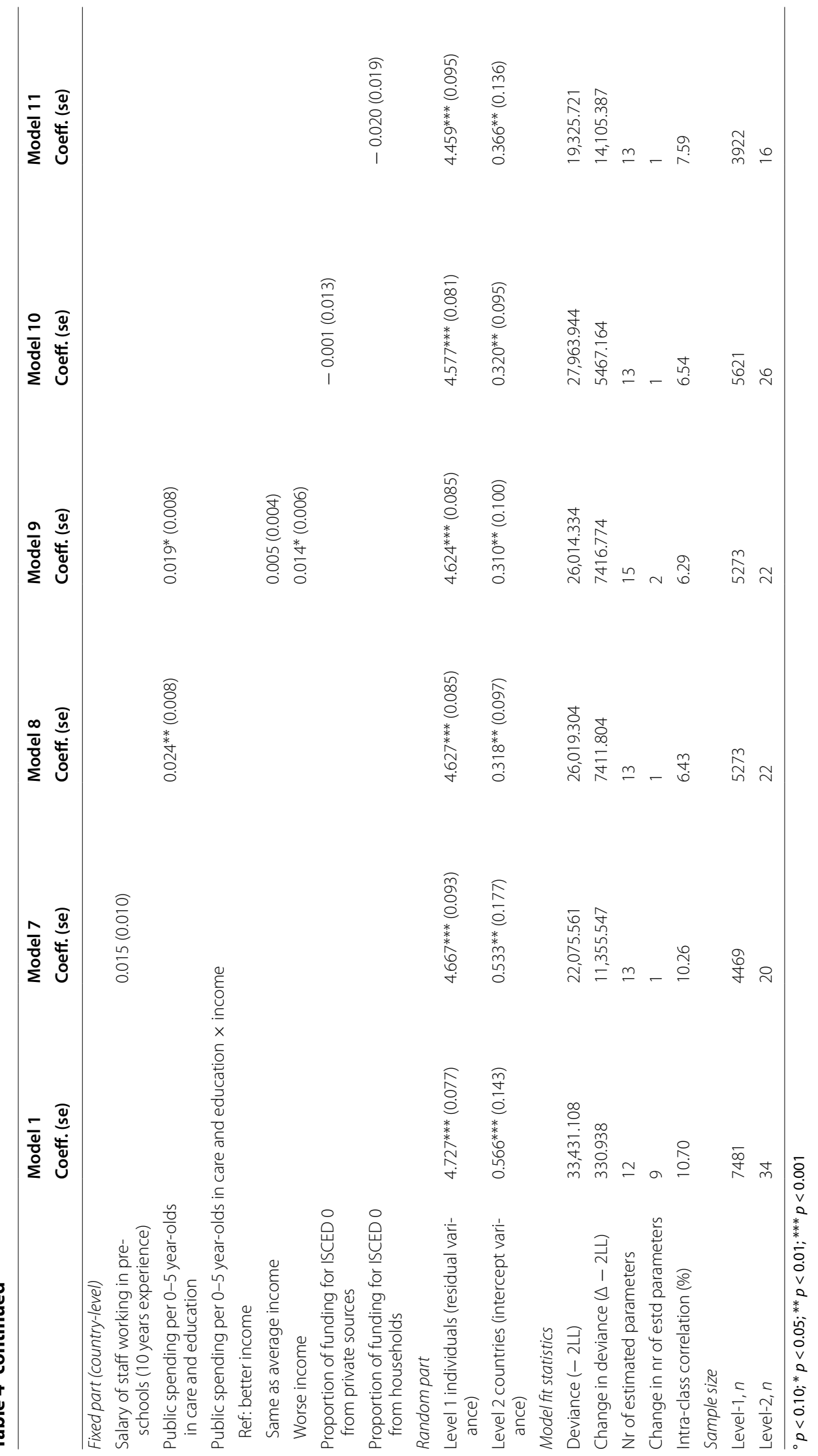




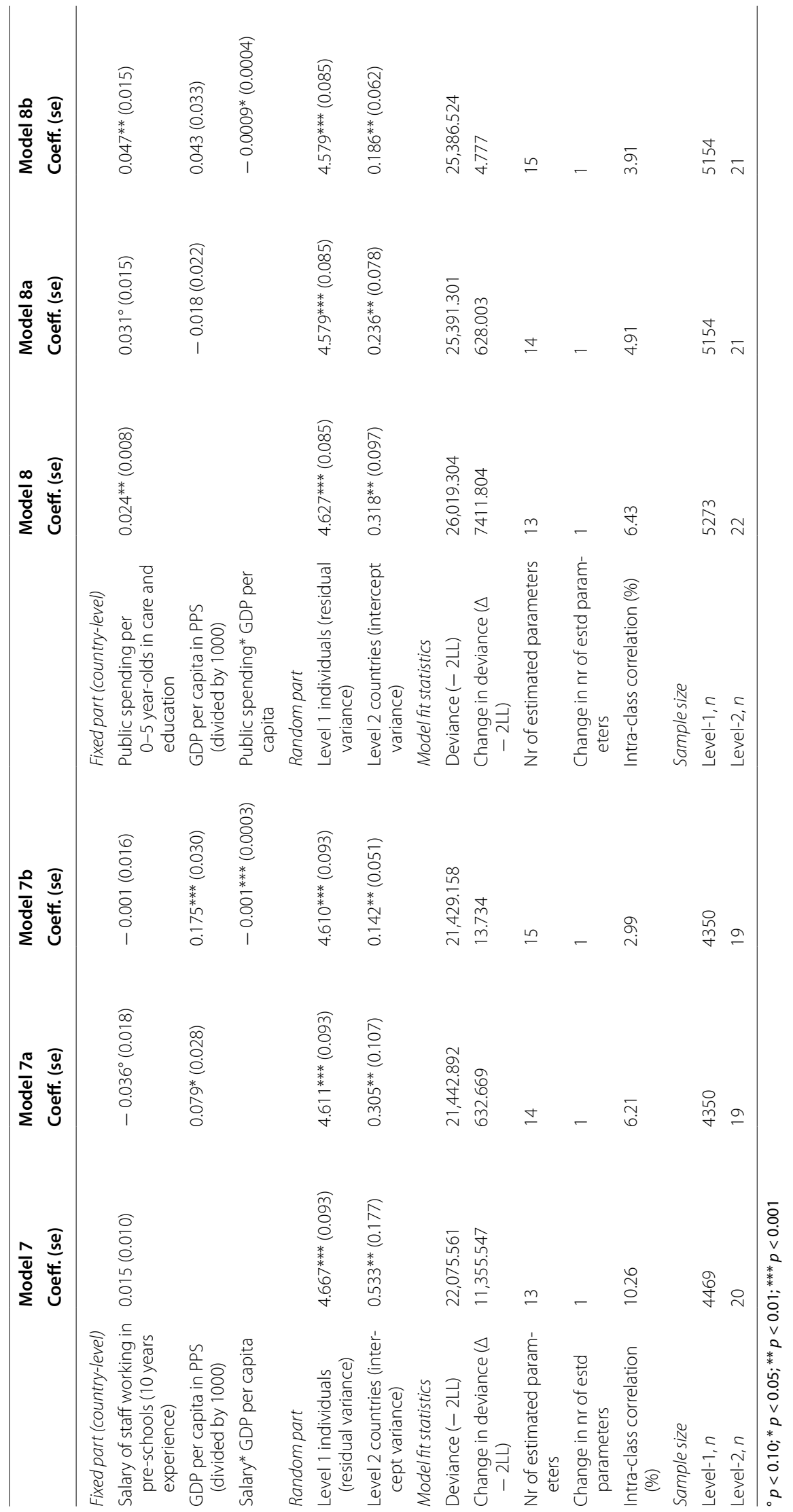




\section{Discussion}

Due to the small country-level sample size in this study, it is a good start to investigate individual-level associations initially. The first variable that has a significant relationship with perceived accessibility at the respondent level is the existence of commercial profitmaking ECEC services for older children of 3-6 years. Private provision at the preschool level is more widespread in Central and Eastern, as well as southern European countries as opposed to the Nordic and Baltic countries. ${ }^{1}$ Nevertheless, there are notable exceptions to both, which makes it difficult to predict which countries would allow for private pre-school provision based on their geographical and socio-economic proximity to each other. For instance, although Ireland and the United Kingdom are the two countries representing liberalism, the former does not allow for private provision while the other does.

Additional provision-related variables such as the start of legal entitlement to ECEC services or the start of the right of free attendance do not have a significant relationship with perceived accessibility. Still, the start of legal entitlement can still be considered as marginally significant at the level of $p<0.10$. It is surprising to see that the start of legal entitlement does not have the expected effect on perceived accessibility, because research indicates that availability of slots is a key element of accessibility (Kreyenfeld and Hank 2000).

Nevertheless, the irrelevance of the start of free entitlement is in line with previous studies that prioritise availability of places over affordability (Del Boca 2002; Farfan-Portet et al. 2011; Kreyenfeld and Hank 2000). However, this variable confines affordability to services being completely free. The fact that provision is not 'free of charge' does not mean that the users find these services unaffordable. Henceforth, these results depict that making the services free of charge is not necessary, as long as there are other measures to make childcare more affordable via means-testing or fee reductions based on the socio-economic situation of users. Finally, the countries that provide free entitlement are mostly Central and Eastern European countries, where perceived accessibility is not high, to begin with.

The element of regulation that has a significant link between perceived accessibility at the individual level is the system being split or integrated (or mixed). Almost half of the European countries have a split system and almost one-fourth of them have partially integrated (mixed) systems. ${ }^{2}$ According to our analyses, ECEC systems are perceived to be most accessible in countries with a unitary system, which is the case in Nordic and Baltic countries as well as Croatia and Slovenia.

None of the two structural quality variables included in this study proved to have a link with the degree of perceived accessibility. This could be due to the fact that the chosen

\footnotetext{
1 The countries that allow for private provision for 3-6 year olds that needs to be financed by the users are Bulgaria, Croatia, Cyprus, France, Germany, Greece, Hungary, Italy, Luxembourg, Malta, Portugal, Romania, Spain, Turkey and the United Kingdom.

The countries that do not allow for private provision for 3-6-year-olds that needs to be funded by the users are Austria, Belgium, Czech Republic, Denmark, Estonia, Finland, Iceland, Ireland, Latvia, Lithuania, Poland, Slovak Republic, Slovenia and Sweden.

2 The European countries with an integrated/unitary ECEC system are Croatia, Estonia, Finland, Iceland, Latvia, Lithuania, Norway, Slovenia and Sweden.

The countries with a mixed (partially integrated) system are Austria, Bulgaria, Denmark, Germany, Spain and the United Kingdom.

The countries with a split ECEC system are Belgium, Cyprus, Czech Republic, France, Greece, Hungary, Ireland, Italy, Luxembourg, Malta, the Netherlands, Poland, Portugal, Romania, Slovakia, Switzerland and Turkey.
} 


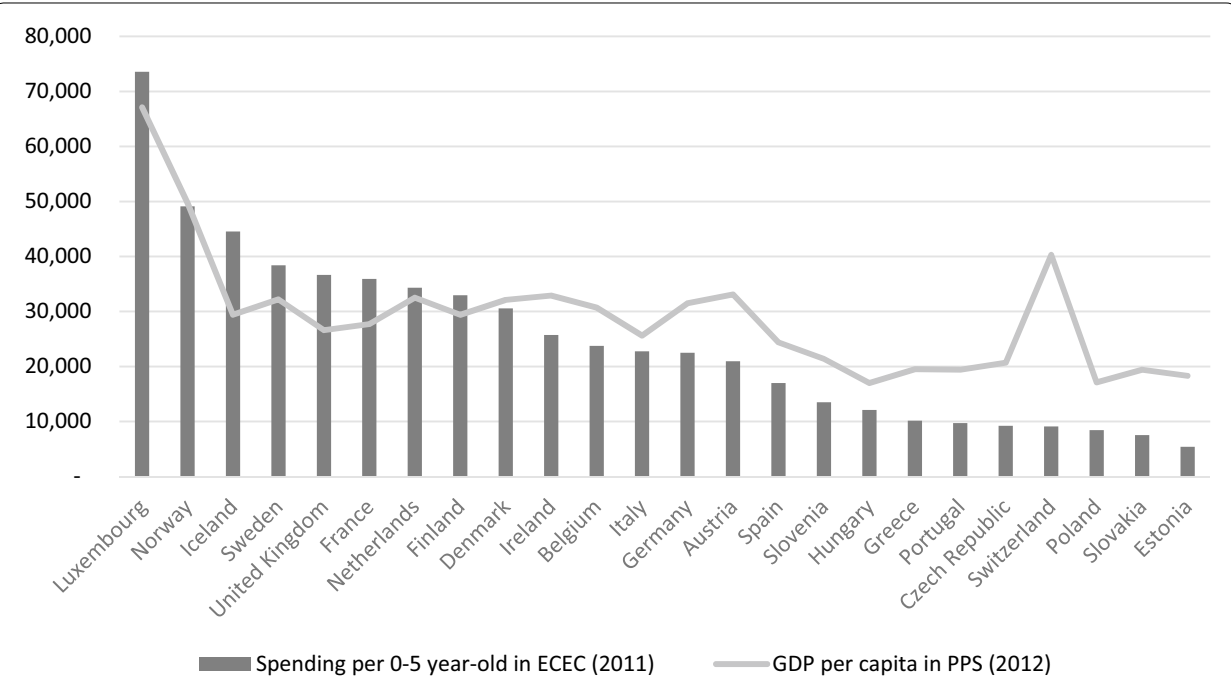

Fig. 4 Spending per 0-5-year-old in ECEC and GDP per capita (Sources: OECD Family Database and Eurostat)

indicators are about quality itself, rather than being a measure of accessibility. This implies that accessibility and quality of ECEC should be treated separately. The measures to improve one are not necessarily effective for the other. As discussed in the introductory sections, accessibility and even affordability have been studied as components of quality to date in many studies. However, accessibility is a pre-requisite in order to start experiencing the more specific aspects of process and outcome quality (Leseman 2014). Among different dimensions of quality, structural quality measures are the more general requirements put into place by governments to standardise the quality at a minimum. Research shows that structural quality measures such as high teacher qualification level, low group size, low children-to-staff ratio and professional development opportunities for teachers have a clear influence on process quality (e.g. classroom organisation, emotional support) (Slot et al. 2015).

The third country-level variable with a significant relationship with perceived accessibility of childcare is public spending per 0-5-year-old in the ECEC system. Not surprisingly, the higher the spending per child, the more accessible childcare is. Figure 4 demonstrates that European countries are highly diverse with regard to their public spending per child in ECEC. Note that one limitation of this variable is the small number of countries for which there is available information. The countries with high spending do not exactly correspond to the countries with the most accessible ECEC (see Figs. 1, 2). Still, the analysis reveals that higher perceived accessibility is significantly correlated with higher spending at the country level. Also note that the positive effect of high spending increases if the country is not very wealthy, but prioritises ECEC spending.

Finally, the finding regarding the irrelevance of the cumulative percentage of preschool funding coming from private sources for the perceived accessibility of the services also supports the argument that making ECEC completely free or low cost is not necessary in order to make it accessible. In order to find better insight on what type of financing structure benefits parents the most, future studies need to look more in-depth into what parents actually pay, how means-testing work and whether there are sufficient 
resources for the disadvantaged families to be included in the system. The indicators in the OECD Family Database regarding the out-of-pocket childcare expenditure of dualand single-earner families were also not significant in our analyses. These results point to the fact that financing needs to be studied on a more case-by-case basis in relation to perceived accessibility.

\section{Limitations and avenues for further research}

There are several limitations to this research, which are mainly related to the unavailability of data at the respondent and country levels. One of the limitations is the lack of a variable clarifying the immigration background of the respondent in European Quality of Life Survey. Research indicates that children with an immigration background are disadvantaged when it comes to access to ECEC (Nusche 2009); however, due to the lack of data we could not control for immigration status. This variable could have been collected in the context of EQLS via various means such as asking whether a family member (or the parents of the family member) migrated into the country, or the language spoken at home and whether it is different from the language(s) of the country. The only available variable that could be used as a proxy to immigration status is the citizenship status of the respondent, with three categories: citizenship of the country one is interviewed in, citizenship of another EU member state and the citizenship of a non-EU country. Using this variable would be an ineffective way of accounting for immigration background because migration may not always be related to citizenship status. The variable is inefficient even if the aim would be to test the effect of citizenship status since there is no further information on the country of citizenship (whether it is an equally developed country, whether it is outside Europe if the third category is the case, etc.).

With regard to the country-level variables, availability of the data is a big problem. The most detailed and up-to-date source of data for this work has been the Eurydice report (2014), which provided a good overview, but still not in-depth data. Moreover, comparability of data across countries is an issue with regard to data being available on different levels. For example, in countries with federal systems, regions may report very different information, and it is not possible to derive countrywide policies from those. Moreover, we could not check for several potential determinants such as curriculum, equity policies, means-testing policies, targeted programmes or (de)centralisation due to the unavailability of comparative data. For this reason, it is important to note that, based on this study, we cannot conclude that affordability and structural quality do not matter for perceived accessibility. Considering the lack of a large sample size, these indicators should be studied further.

One of the shortcomings in the field of ECEC policy research we had to navigate through has been the non-standard ECEC terminology across Europe. Even though our preferred term has been ECEC, given the use of "childcare" in the EQLS data and some other publications in the field, we used the two terms almost interchangeably. Some of the country-level data used for this research are available for the whole age range of 0-6 years of age, while some are either for the period of $0-3$ or 3-6 years of age. Despite our best efforts, we could not completely take into account the whole $0-6$ age range. Yet, note that throughout the article, we used the term ECEC when referring to the ECEC 
policies. The term "childcare", however, was used mostly to refer to the empirical side of the present study.

Finally, a comparison between the subjective (perceived) accessibility and objective accessibility would be interesting to pursue. Having the possibility to measure perceived accessibility using the EQLS data is already a big step forward. The next step would be developing an 'objective childcare accessibility index', where access to ECEC services is evaluated by a third party in a cross-country manner. The objective accessibility index would also serve as a diagnostic tool whether access improves across countries as intended by policy makers.

\section{Concluding remarks}

Provision, regulation and financing are the three pillars of the institutional setting of early childhood education and care. This article addresses a gap in the literature by examining the effect of these system characteristics on the public perception of accessibility of services in a comparative manner across Europe. At the individual- or household-level, female, younger, employed and lower-income respondents and those living in urban areas find childcare services less accessible.

According to the present study, childcare is perceived as more accessible in countries that (1) do not allow private commercial profit-making ECEC services for 3-6-year-old children, (2) adopt a unitary ECEC system where services for 0-3- and 3-6-year-olds are harmonised and (3) provide generous public support per 0-5-year-old child in the ECEC system. The latter has an even stronger effect on the families with an income below average. These results are interesting because they offer evidence with regard to the policies that contribute to increased perceived accessibility of childcare by families. The insights offered in this article are helpful to policy makers who need further direction for the making of future childcare policies.

\section{Authors' contributions}

The first author, ÖÜ, has conducted the literature review, data analysis and interpretation of the results. The second author, TB, has contributed to the methodology, data analysis and literature review. The third author, IN, has contributed to the theoretical framework used in this article. All authors read and approved the final manuscript.

Acknowledgements

Not applicable.

Competing interests

The authors declare that they have no competing interests.

Availability of data and materials

The European Quality of Life Survey (EQLS) data used in this study are publicly available (upon registration) in the website of UK Data Archive.

Consent for publication

Not applicable.

Ethics approval and consent to participate

Not applicable.

Funding

This research was conducted within the context of the CARE project that received funding from the European Union's Seventh Framework Programme for research, technological development and demonstration under Grant Agreement Number 613318

\section{Publisher's Note}

Springer Nature remains neutral with regard to jurisdictional claims in published maps and institutional affiliations. 
Received: 22 March 2017 Accepted: 13 February 2018

Published online: 27 February 2018

\section{References}

Anderson, K. J., \& Minke, K. M. (2007). Parent involvement in education: Toward an understanding of parents' decision making. The Journal of Educational Research Bloomington., 100(5), 311-323.

Asparouhov, T. (2006). General multi-level modeling with sampling weights. Communications in Statistics-Theory and Methods, 35(3), 439-460. https://doi.org/10.1080/03610920500476598.

Authors. (unpublished article). Early Childhood Education and Care take-up among disadvantaged groups in Europe: The role of institutional setting.

Barbarin, O. A., McCandies, T., Early, D., Clifford, R. M., Bryant, D., Burchinal, M., et al. (2006). Quality of prekindergarten: What families are looking for in public sponsored programs. Early Education and Development, 17(4), 619-642. https://doi.org/10.1207/s15566935eed1704_6.

Barnes, J., Leach, P., Sylva, K., Stein, A., Malmberg, L.-E., Families, C., et al. (2006). Infant care in England: Mothers' aspirations, experiences, satisfaction and caregiver relationships. Early Child Development and Care, 176(5), 553-573. https://doi. org/10.1080/03004430500317408.

Bastos, P., \& Cristia, J. (2012). Supply and quality choices in private child care markets: Evidence from São Paulo. Journal of Development Economics, 98(2), 242-255. https://doi.org/10.1016/j.jdeveco.2011.08.001.

Bennett, J. (2004). Early education financing: What is useful to know? UNESCO Policy Brief on Early Childhood. Retrieved from http://unesdoc.unesco.org/images/0013/001374/137412e.pdf. Accessed 19 Feb 2018.

Bircan, T. (2012). Community structure and ethnocentrism. A multilevel approach: A case study of flanders (Belgium). Leuven: KU Leuven.

Blohm, M., \& Koch, A. (2009). Item nonresponse in the European Social Survey. ASK. Research \& Methods, 18, 45-65.

Bowers, A. P., Strelitz, J., Allen, J., \& Donkin, A. (2012). An equal start: Improving outcomes in children's centres. Brussels: UCL Institute of Health Equity. Retrieved from http://www.kindengezin.be/img/an-equal-start-outcomes.pdf. Accessed 19 Feb 2018.

Burchinal, M., Howes, C., \& Kontos, S. (2002). Structural predictors of child care quality in child care homes. Early Childhood Research Quarterly, 17(1), 87-105. https://doi.org/10.1016/S0885-2006(02)00132-1.

Cai, T. (2013). Investigation of ways to handle sampling weights for multilevel model analyses. Sociological Methodology, 43(1), 178-219. https://doi.org/10.1177/0081175012460221.

Carle, A. C. (2009). Fitting multilevel models in complex survey data with design weights: Recommendations. BMC Medical Research Methodology, 9, 49. https://doi.org/10.1186/1471-2288-9-49.

Ceglowski, D., \& Bacigalupa, C. (2002). Four perspectives on child care quality. Early Childhood Education Journal, 30(2), 87-92. https://doi.org/10.1023/A:1021245017431.

Chantala, K., Suchindran, C. M., \& Blanchette, D. (2005). Adjusting for unequal selection probability in multilevel models: A comparison of software packages. IDEAS Working Paper Series from RePEc; St. Louis. Retrieved from https://searchproquest-com.kuleuven.ezproxy.kuleuven.be/docview/1697750310?rfr_id=info\%3Axri\%2Fsid\%3Aprimo.

Chung, H., \& Meuleman, B. (2017). European parents'attitudes towards public childcare provision: The role of current provisions, interests and ideologies. European Societies, 19(1), 49-68. https://doi.org/10.1080/14616696.2016.1235218.

Cleveland, J., Susman-Stillman, A., \& Halle, T. (2013). Parental perceptions of quality in early care and education. Retrieved from http://www.childtrends.org/wp-content/uploads/2013/12/2013-44ParentalPerceptionsofQuality.pdf. Accessed 19 Feb 2018.

Cunha, F., Heckman, J. J., Lochner, L., \& Masterov, D. V. (2006). Interpreting the evidence on life cycle skill formation. Handbook of the Economics of Education, 1, 697-812.

Davis, E. E., \& Connelly, R. (2005). The influence of local price and availability on parents' choice of child care. Population Research and Policy Review, 24(4), 301-334. https://doi.org/10.1007/s11113-005-8515-y.

Del Boca, D. (2002). The effect of child care and part time opportunities on participation and fertility decisions in Italy. Journal of Population Economics, 15(3), 549-573. https://doi.org/10.1007/s001480100089.

Dumčius, R., Peeters, J., Hayes, N., Van Landeghem, G., Siarova, H., Peciukonytè, L., Ceneric, I., Hulpia, H. (2014). Study on the effective use of early childhood education and care (ECEC) in preventing early school leaving (ESL): Annex 1. Literature review. Luxembourg: Publications Office of the European Union. Retrieved from http://bookshop.europa.eu/en/ study-on-the-effective-use-of-early-childhood-education-and-care-ecec-in-preventing-early-school-leaving-eslpbNC0414323/.

Education at a Glance. (2013). Table B3.2a-Relative proportions of public and private expenditure on educational institutions, by level of education (2000, 2010). OECD. Retrieved from http://www.oecd-ilibrary.org/education/education-at-aglance-2013/relative-proportions-of-public-and-private-expenditure-on-educational-institutions-by-level-of-education-2000-2010_eag-2013-table98-en.

Education at a Glance. (2015). Table D3.1a-Teachers'statutory salaries, based on typical qualifications, at different points in teachers' careers (2013). OECD. Retrieved from http://www.oecd-ilibrary.org/education/education-at-a-glance-2015/ teachers-statutory-salaries-based-on-typical-qualifications-at-different-points-in-teachers-careers-2013_eag2015-table258-en. Accessed 19 Feb 2018.

Eurofound. (2013a). 3rd european quality of life survey: Weighting report-EU27 and non-EU countries. GfK EU3C. Retrieved from http://www.eurofound.europa.eu/sites/default/files/ef_files/surveys/egls/2011/documents/egls3weighting. pdf. Accessed 19 Feb 2018.

Eurofound. (2013b). Third European Quality of Life Survey—Quality of society and public services (p. 108). Luxembourg: Publications Office of the European Union. Retrieved from http://www.eurofound.europa.eu/sites/default/files/ ef_publication/field_ef_document/ef1361en.pdf. 
Eurydice. (2014). Key data on early childhood education and care in Europe (Eurydice and Eurostat Report). Luxembourg: Publications Office of the European Union. Retrieved from http://eacea.ec.europa.eu/education/eurydice.

EQLS (2012). European Quality of Life Survey, 2011-2012 [data collection], 2nd Edn. UK Data Service. SN: 7316. doi:https:// doi.org/10.5255/UKDA-SN-7316-2.

Farfan-Portet, M.-I., Lorant, V., \& Petrella, F. (2011). Access to childcare services: The role of demand and supply-side policies. Population Research and Policy Review, 30(2), 165-183. https://doi.org/10.1007/s11113-010-9184-z.

Forry, N. D., Simkin, S., Wheeler, E. J., \& Bock, A. (2013). 'You know how it makes you feel': Low-income parents' childcare priorities and definitions of ideal high-quality childcare. Journal of Children and Poverty, 19(2), 107-126. https://doi. org/10.1080/10796126.2013.843508.

Foubert, J., Levecque, K., Van Rossem, R., \& Romagnoli, A. (2014). Do welfare regimes influence the association between disability and self-perceived health? A multilevel analysis of 57 countries. Social Science and Medicine, 117, 10-17. https://doi.org/10.1016/j.socscimed.2014.07.023.

Fram, M. S., \& Kim, J. (2008). Race/ethnicity and the start of child care: A multi-level analysis of factors influencing first child care experiences. Early Childhood Research Quarterly, 23(4), 575-590. https://doi.org/10.1016/j. ecresq.2008.04.002.

Fuller, B., Holloway, S. D., Rambaud, M., \& Eggers-Pierola, C. (1996). How do mothers choose child care? Alternative cultural models in poor neighborhoods, Albany. Sociology of Education., 69(2), 83.

Gamble, W. C., Ewing, A. R., \& Wilhlem, M. S. (2009). Parental perceptions of characteristics of non-parental child care: Belief dimensions, family and child correlates. Journal of Child and Family Studies, 18(1), 70-82. https://doi. org/10.1007/s10826-008-9208-z.

Geoffroy, M.-C., Séguin, J. R., Lacourse, É., Boivin, M., Tremblay, R. E., \& Côté, S. M. (2012). Parental characteristics associated with childcare use during the first 4 years of life: Results from a representative cohort of Québec Families. Canadian Journal of Public Health Revue Canadienne de Sante Publique, 103(1), 76-80.

Ghysels, J., \& Van Lancker, W. (2011). The unequal benefits of activation: An analysis of the social distribution of family policy among families with young children. Journal of European Social Policy, 21(5), 472-485. https://doi. org/10.1177/0958928711418853.

Goldstein, H. (2003). Multilevel statistical models (3rd ed.). London: Oxford University Press.

Habibov, N. (2012). Early childhood care and education attendance in Central Asia. Children and Youth Services Review, 34(4), 798-806. https://doi.org/10.1016/j.childyouth.2012.01.006.

Hayes, A. F. (2006). A primer on multilevel modeling. Human Communication Research, 32(4), 385-410. https://doi. org/10.1111/j.1468-2958.2006.00281.x.

Heckman, J. J. (2006). Skill formation and the economics of investing in disadvantaged children. Science, 312(5782), 1900-1902. https://doi.org/10.1126/science.1128898.

Henly, J. R., \& Lyons, S. (2000). The negotiation of child care and employment demands among low-income parents. Journal of Social Issues, 56(4), 683-706. https://doi.org/10.1111/0022-4537.00191.

Herczog, M. (2012). Rights of the child and early childhood education and care in Europe. European Journal of Education, 47(4), 542-555. https://doi.org/10.1111/ejed.12008.

Hofferth, S. L., \& Wissoker, D. A. (1992). Price, quality, and income in child care choice. The Journal of Human Resources, 27(1), 70-111. https://doi.org/10.2307/145913.

Hox, J. J., \& Kreft, I. G. G. (1994). Multilevel analysis methods. Sociological Methods \& Research, 22(3), 283-299. https://doi. org/10.1177/0049124194022003001.

IBM Corp. (2015). IBM SPSS statistics for windows (Version 23.0). Armonk: IBM Corp.

Kaga, Y., Bennett, J., \& Moss, P. (2010). Caring and learning together: Study on the integration of ECCE within education. Paris: UNESCO. Retrieved from http://unesdoc.unesco.org/images/0018/001878/187818e.pdf. Accessed 19 Feb 2018.

Kaplan, D., \& Elliott, P. R. (1997). A model-based approach to validating education indicators using multilevel structural equation modeling. Journal of Educational and Behavioral Statistics, 22(3), 323-347. https://doi.org/10.2307/1165288.

Kim, J., \& Fram, M. S. (2009). Profiles of choice: Parents' patterns of priority in child care decision-making. Early Childhood Research Quarterly, 24(1), 77-91. https://doi.org/10.1016/j.ecresq.2008.10.001.

Kreyenfeld, M., \& Hank, K. (2000). Does the availability of child care influence the employment of mothers? Findings from western Germany. Population Research and Policy Review, 19(4), 317-337. https://doi.org/10.1023/A:1026556309080.

Lehrer, J. S., Lemay, L., \& Bigras, N. (2015). parental perceptions of child care quality in centre-based and home-based settings: Associations with external quality ratings. International Journal of Early Childhood, 47(3), 481-497. https://doi. org/10.1007/s13158-015-0147-8.

Leseman, P. P. M. (2009). The impact of high quality education and care on the development of young children: Review of the literature. In: Tackling social and cultural inequalities through early childhood education and care in Europe (pp. 17-49). Brussels: Education, Audiovisual and Culture Executive Agency. Retrieved from http://eacea.ec.europa.eu/ education/eurydice/documents/thematic_reports/098EN.pdf.

Leseman, P. P. M. (2014). Quality of the early years provisions: A European perspective. Utrecht, the Netherlands: Utrecht University Department of Special Education. Retrieved from http://www.uis.no/getfile.php/HF/IBU/TODDLER/Dokumenter/Sluttkonferanse\%20Ghent\%202013/Plenary\%20sessions/Keynote\%20Leseman\%20-\%20Quality\%20of\%20 the\%20early\%20years\%20provisions\%20-\%208\%20October\%202013\%20(print).pdf. Accessed 19 Feb 2018.

Li-Grining, C. P., \& Coley, R. L. (2006). Child care experiences in low-income communities: Developmental quality and maternal views. Early Childhood Research Quarterly, 21(2), 125-141. https://doi.org/10.1016/j.ecresq.2006.04.001.

Liu, M. (2015). An ecological review of literature on factors influencing working mothers'child care arrangements. Journal of Child and Family Studies, 24(1), 161-171. https://doi.org/10.1007/s10826-013-9822-2.

Mahon, R. (2002). Child care: Toward what kind of 'Social Europe'? Social Politics: International Studies in Gender, State \& Society, 9(3), 343-379. https://doi.org/10.1093/sp/9.3.343.

Manning, M., Garvis, S., Fleming, C., \& Wong, G. T. W. (2017). The Relationship between teacher qualification and the quality of the early childhood care and learning environment: A systematic review. Campbell Collaboration. Retrieved from https://www.campbellcollaboration.org/library/teacher-qualification-and-quality-of-early-childhood-care-andlearning.html. Accessed 19 Feb 2018. 
McLean, C. (2014). Market managers and market moderators: Early childhood education and care provision, finance and regulation in the United Kingdom and United States. Journal of European Social Policy, 24(2), 122-134. https://doi. org/10.1177/0958928713517916.

Meyers, M. K., \& Gornick, J. C. (2003). Public or private responsibility? Early childhood education and care, inequality, and the welfare State. Journal of Comparative Family Studies, 34(3), 379-411.

Molinuevo, D. (2015). Childcare for all: Making early childhood education and care more accessible and inclusive. Retrieved February 11 2016, from http://ec.europa.eu/social/main.jsp?catld=89\&furtherNews=yes\&langld=en\&ne wsld $=2420$.

Muthén, B. O. (1994). Multilevel covariance structure analysis. Sociological Methods \& Research, 22(3), 376-398. https://doi. org/10.1177/0049124194022003006.

Myers, R. G. (2000). Financing early childhood education and care services. International Journal of Educational Research, 33(1), 75-94. https://doi.org/10.1016/S0883-0355(99)00044-0.

Neuman, M. J. (2009). The politics of (de)centralisation: Early care and education in France and Sweden. In K. Scheiwe \& H. Willekens (Eds.), Child care and preschool development in Europe: Institutional perspectives (pp. 157-179). Basingstoke: Palgrave Macmillan.

Nichd, E. C. C. R. N. (2002). Child-care structure $\rightarrow$ process $\rightarrow$ outcome: Direct and indirect effects of child-care quality on young children's development. Psychological Science, 13(3), 199-206. https://doi.org/10.1111/1467-9280.00438.

Noailly, J., \& Visser, S. (2009). The impact of market forces on child care provision: Insights from the 2005 child care act in the Netherlands. Journal of Social Policy, 38(03), 477-498. https://doi.org/10.1017/S0047279409003109.

Nusche, D. (2009). What works in migrant education? (OECD Education Working Papers). Paris: Organisation for Economic Co-Operation and Development. Retrieved from http://www.oecd-ilibrary.org/content/workingpaper/227131784531. Accessed 19 Feb 2018.

OECD. (2001). Starting strong. Paris: Organisation for Economic Co-Operation and Development. Retrieved from http:// www.oecd-ilibrary.org.kuleuven.ezproxy.kuleuven.be/education/starting-strong_9789264192829-en. Accessed 19 Feb 2018.

OECD. (2006). Starting strong II. Paris: Organisation for Economic Co-Operation and Development. Retrieved from http:// www.oecd-ilibrary.org/content/book/9789264035461-en. Accessed 19 Feb 2018.

OECD. (2012). Starting strong III. Paris: Organisation for Economic Co-Operation and Development. Retrieved from http:// www.oecd-ilibrary.org/content/book/9789264123564-en. Accessed 19 Feb 2018.

OECD Family Database. (2011). PF1.6 Public spending by age of children. Organisation for economic co-operation and development. Retrieved from http://www.oecd.org/social/family/database.htm. Accessed 19 Feb 2018.

Penn, H. (2009). International perspectives on quality in mixed economies of childcare. National Institute Economic Review, 207(1), 83-89. https://doi.org/10.1177/0027950109103687.

Peyton, V., Jacobs, A., O'Brien, M., \& Roy, C. (2001). Reasons for choosing child care: Associations with family factors, quality, and satisfaction. Early Childhood Research Quarterly, 16(2), 191-208. https://doi.org/10.1016/ S0885-2006(01)00098-9.

Pfeffermann, D. (1993). The role of sampling weights when modeling survey data. International Statistical Review/Revue Internationale de Statistique, 61(2), 317-337. https://doi.org/10.2307/1403631.

Pfeffermann, D., Moura, D. S., Antonio, F., Silva, D. N., \& Luis, P. (2006). Multi-level modelling under informative sampling. Biometrika, 93(4), 943-959. https://doi.org/10.1093/biomet/93.4.943.

Pfeffermann, D., Skinner, C. J., Holmes, D. J., Goldstein, H., \& Rasbash, J. (1998). Weighting for unequal selection probabilities in multilevel models. Journal of the Royal Statistical Society: Series B (Statistical Methodology), 60(1), 23-40. https:// doi.org/10.1111/1467-9868.00106.

Phillips, D., Mekos, D., Scarr, S., McCartney, K., \& Abbott-Shim, M. (2000). Within and beyond the classroom door: Assessing quality in child care centers. Early Childhood Research Quarterly, 15(4), 475-496. https://doi.org/10.1016/ S0885-2006(01)00077-1.

Phillipsen, L. C., Burchinal, M. R., Howes, C., \& Cryer, D. (1997). The prediction of process quality from structural features of child care. Early Childhood Research Quarterly, 12(3), 281-303. https://doi.org/10.1016/S0885-2006(97)90004-1.

Pungello, E. P., \& Kurtz-Costes, B. (1999). Why and how working women choose child care: A review with a focus on infancy. Developmental Review, 19(1), 31-96. https://doi.org/10.1006/drev.1998.0468.

Rose, K. K., \& Elicker, J. (2010). Maternal child care preferences for infants, toddlers, and preschoolers: The disconnect between policy and preference in the USA. Community, Work \& Family, 13(2), 205-229. https://doi. org/10.1080/13668800903314366.

Rosenthal, K. R., Gesten, E. L., \& Shiffman, S. (1986). Gender and sex role differences in the perception of social support. Sex Roles., 14(9), 481-499.

Schlueter, E., Meuleman, B., \& Davidov, E. (2013). Immigrant integration policies and perceived group threat: A multilevel study of 27 western and eastern European countries. Social Science Research, 42(3), 670-682. https://doi. org/10.1016/j.ssresearch.2012.12.001.

Seo, S. (2003). Early child care choices: A theoretical model and research implications. Early Child Development and Care, 173(6), 637-650. https://doi.org/10.1080/0300443032000088230.

Sibley, E., Dearing, E., Toppelberg, C. O., Mykletun, A., \& Zachrisson, H. D. (2015). Do increased availability and reduced cost of early childhood care and education narrow social inequality gaps in utilization? Evidence from Norway. International Journal of Child Care and Education Policy. https://doi.org/10.1007/s40723-014-0004-5.

Slot, P. L., Lerkkanen, M.-K., \& Leseman, P. P. M. (2015). D2.2: The relations between structural quality and process quality in European early childhood education and care provisions: Secondary analyses of large scale studies in five countries. Retrieved from http://ecec-care.org/fileadmin/careproject/Publications/reports/CARE_WP2_D2_2_Secondary_data_analyses.pdf. Accessed 19 Feb 2018.

Sosinsky, L. S., Lord, H., \& Zigler, E. (2007). For-profit/nonprofit differences in center-based child care quality: Results from the National Institute of Child Health and Human Development Study of Early Child Care and Youth Development. Journal of Applied Developmental Psychology, 28(5-6), 390-410. https://doi.org/10.1016/j.appdev.2007.06.003. 
Sylva, K., Stein, A., Leach, P., Barnes, J., \& Malmberg, L.-E. (2007). Family and child factors related to the use of nonmaternal infant care: An English study. Early Childhood Research Quarterly, 22(1), 118-136. https://doi.org/10.1016/j. ecresq.2006.11.003.

Tang, S., Coley, R. L., \& Votruba-Drzal, E. (2012). Low-income families' selection of child care for their young children. Children and Youth Services Review, 34(10), 2002-2011. https://doi.org/10.1016/j.childyouth.2012.06.012.

van Oorschot, W., Reeskens, T., \& Meuleman, B. (2012). Popular perceptions of welfare state consequences: A multilevel, cross-national analysis of 25 European countries. Journal of European Social Policy, 22(2), 181-197. https://doi. org/10.1177/0958928711433653.

Vandenbroeck, M., De Visscher, S., Van Nuffel, K., \& Ferla, J. (2008). Mothers' search for infant child care: The dynamic relationship between availability and desirability in a continental European welfare state. Early Childhood Research Quarterly, 23(2), 245-258. https://doi.org/10.1016/j.ecresq.2007.09.002.

Vandenbroeck, M., \& Lazzari, A. (2014). Accessibility of early childhood education and care: A state of affairs. European Early Childhood Education Research Journal, 22(3), 327-335. https://doi.org/10.1080/1350293X.2014.912895.

White, L. A., \& Friendly, M. (2012). Public funding, private delivery: States, markets, and early childhood education and care in liberal welfare states-a comparison of Australia, the UK, Quebec, and New Zealand. Journal of Comparative Policy Analysis: Research and Practice, 14(4), 292-310. https://doi.org/10.1080/13876988.2012.699789.

Zachrisson, H. D., Janson, H., \& Nærde, A. (2013). Predicting early center care utilization in a context of universal access. Early Childhood Research Quarterly, 28(1), 74-82. https://doi.org/10.1016/j.ecresq.2012.06.004.

\section{Submit your manuscript to a SpringerOpen ${ }^{\circ}$ journal and benefit from:}

- Convenient online submission

\section{- Rigorous peer review}

- Open access: articles freely available online

- High visibility within the field

- Retaining the copyright to your article

Submit your next manuscript at $\gg$ springeropen.com 